\title{
Microextraction techniques
}

\author{
M. Valcárcel • S. Cárdenas • R. Lucena
}

Published online: 31 January 2014

(C) Springer-Verlag Berlin Heidelberg 2014

Sample treatment has been the focus of intensive research in the last 20 years. The low concentration of the target analytes, the large amount of potential interferents and the incompatibility of the sample matrix with the instrumental techniques are the main reasons for these research efforts. In most methods, this step is unavoidable, having a clear influence on the quality of the final analytical results. Sample treatment has evolved following six general trends, namely, simplification, automation, miniaturization, expeditiousness, economical aspects, and safety aspects. In this context, the new microextraction techniques, including solid-phase microextraction (SPME) and liquid-phase microextraction (LPME), have emerged as a response to those requirements that in some cases are unattainable with classical techniques. A literature survey, restricted to the last 20 years, clearly demonstrates the increasing impact of these novel techniques, which have an overall $h$ index of 119 .

The observed trend can be attributed not only to the development of new modalities but also to the improvement of existing ones by the use of innovative approaches and materials. In this sense, the use of nanostructured materials (basically in solid-phase extraction and SPME modes) and the use of ionic liquids (in both SPME and LPME modes) are key milestones in this evolution. The usefulness of microextraction techniques is beyond doubt and their complete acceptance in routine analytical laboratories depends on their successful automation, even integration, with conventional analytical instruments.

Published in the topical collection Microextraction Techniques with guest editors Miguel Valcárcel Cases, Soledad Cárdenas Aranzana and Rafael Lucena Rodríguez.

M. Valcárcel $(\varangle) \cdot S$. Cárdenas $\cdot R$. Lucena

Department of Analytical Chemistry, Institute of Fine Chemistry and Nanochemistry, Marie Curie Building (Annex), Campus de

Rabanales, University of Córdoba, 14071 Córdoba, Spain

e-mail: qa1vacam@uco.es
This topical collection of Analytical and Bioanalytical Chemistry is devoted to new approaches of microextraction techniques. The topical collection includes up to 15 scientific contributions, including critical reviews on SPME and LPME, discussing the state of the art and future trends as well as the applicability of these miniaturized techniques in specific areas, such as food analysis and medical diagnosis. The original research articles are equally distributed between liquid and solid extraction modes. The development of new miniaturized units and hybrid extraction media and the evaluation of microextraction tools for problem solving in environmental and food fields are also presented. We are aware that not all topics have been covered, but this issue offers a general view of the potential of LPME and SPME techniques, which can be useful to the readers of Analytical and Bioanalytical Chemistry to understand the role that these miniaturized sample treatments will have in the redesign of routine laboratories.

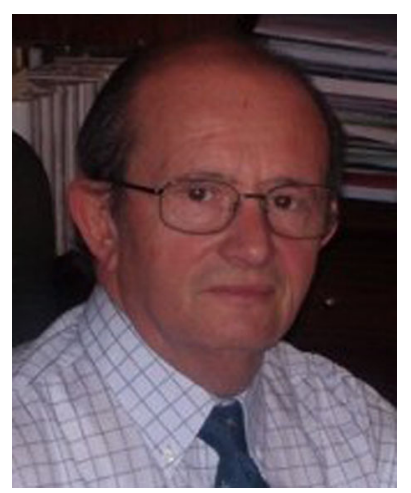

Miguel Valcárcel has been Full Professor of Analytical Chemistry at the University of Córdoba since 1976. He is the author and coauthor of 800 scientific articles (with an $h$ index of 41), seven monographs, eight textbooks and 16 book chapters. He was the coordinator of 25 Spanish research scientific projects and 14 of international nature, as well as 12 contracts with private firms, and was the promoter of a spin-off devoted to nanotechnology. He is the recipient of relevant scientific national (e.g. Award in Chemistry in Spain, 2006) and international (e.g. Robert Boyle Medal of the Royal Society of Chemistry, 2004) prizes as well as the recipient of an honorary doctorate from the University of Valencia (Spain). 


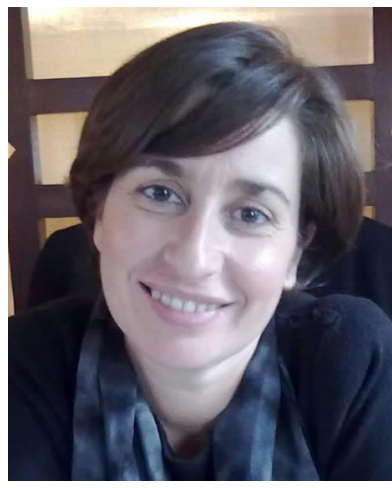

Soledad Cárdenas is Full Professor of Analytical Chemistry at the University of Córdoba. Her research interests comprise advances in miniaturized sample preparation techniques and analytical nanoscience and nanotechnology. She has coauthored about 150 scientific articles, 14 book chapters and a textbook on automation and miniaturization in analytical chemistry. She has participated in 11 national and regional projects, four European projects and five research contracts with national and international companies.

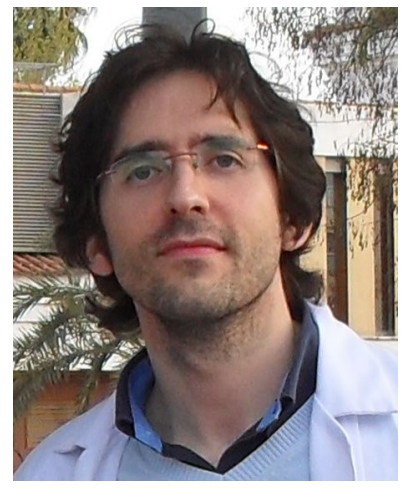

Rafael Lucena has been Associate Professor of Analytical Chemistry at the University of Córdoba since 2010. His main research interests comprise different areas, such as the development of new microextraction techniques, especially those which integrate the stirring and extraction elements in the same devices. Moreover, he is interested in the use of novel materials (e.g. ionic liquids and nanoparticles) in this context. Currently, he is working on the development of chemical (molecularly imprinted polymers) and biorecognition (aptamers) extraction phases. He has coauthored about 60 scientific articles and three book chapters. 